can define (through calculation) what the 'true' ${ }^{14} \mathrm{C}$ age will be (the consensus value) and then we can estimate for each laboratory, whether there is a constant offset (or a bias) from this consensus. The current program of inter-laboratory comparisons has afforded an opportunity for laboratories to assess their accuracy. In each intercomparison, the consensus values for the unknown age samples was calculated and reported. Figure 2, shows the offset (and 95\% confidence interval) for individual laboratories based on the dendrochronologically dated samples included in FIRI. The sample dendro-ages were 3200-3239 BC, 3299 - 3257 BC and 313-294 BC.

\section{Conclusions}

Analyses of results from FIRI and phase 1 of VIRI support the fact that radiocarbon laboratories are generally accurate and precise. The results from FIRI are significant in that they show broad agreement between measurements made in different laboratories on a wide range of materials, and they also demonstrate no statistically significant difference between measurements made by radiometric or AMS techniques. As a result of the inter-comparison program, an extensive suite of natural reference materials (such as wood, carbonate, etc) spanning the applied ${ }^{14} \mathrm{C}$ timescale has been created by the ${ }^{14} \mathrm{C}$ dating community.
These can now be used by ${ }^{14} \mathrm{C}$ labs to improve their dating accuracy and are thus of great benefit to the users of ${ }^{14} \mathrm{C}$ dates.

\section{Acknowledgements}

FIRI and VIRI are supported by EC FPIV programme and English Heritage. The assistance of sample providers is gratefully acknowledged, in addition to the support of all participating labs.

\section{References}

Scott, E.M., 2003: The Third International Radiocarbon Intercomparison (TIRI) and The Fourth International Radiocarbon Intercomparison (FIRI), Radiocarbon, 45(2):135-328.

Scott, E.M., Cook, G.T., Naysmith, P., Bryant, C. and O'Donnell, D., A report on phase 1 of the 5th International Radiocarbon inter-comparison (VIRI), Radiocarbon, in prep.

\title{
IntCal and the future of radiocarbon calibration
}

\author{
P. J. Reimer ${ }^{1}$, E. Bard ${ }^{2}$, C. Buck ${ }^{3}$, T. P. Gullderson ${ }^{4,5}$, A. HogG ${ }^{6}$, K. Hughen ${ }^{7}$, B. Kromer ${ }^{8}$, R. Reimer ${ }^{1}$, J. Southon ${ }^{9}$, C. S. M. Turney ${ }^{10}$, J. van der

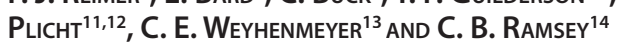

${ }^{1}$ CHRONO Centre for Climate, the Environment, and Chronology, Queen's University Belfast, UK; p.j.reimer@qub.ac.uk ${ }^{2}$ CEREGE, UMR-6635, Aix-en-Provence, France; ${ }^{3}$ Department of Probability and Statistics, University of Sheffield, UK; ${ }^{4}$ Center for Accelerator Mass Spectrometry L-397, Lawrence Livermore National Laboratory, USA; ${ }^{5}$ Ocean Sciences Department, University of California, Santa Cruz, USA; ${ }^{6}$ Radiocarbon Dating Laboratory, University of Waikato, Hamilton, New Zealand; ${ }^{7}$ Department of Marine Chemistry \& Geochemistry, Woods Hole Oceanographic Institution, USA; ${ }^{8} \mathrm{Heidelberger}$ Akademie der Wissenschaften, Heidelberg, Germany; ${ }^{9}$ Department of Earth System Science, University of California, Irvine, USA; ${ }^{10} \mathrm{GeoQ}$ UEST Research Centre, School of Earth and Environmental Sciences, University of Wollongong, Australia; ${ }^{11}$ Centrum voor Isotopen Onderzoek, Rijksuniversiteit Groningen, Groningen, Netherlands; ${ }^{12}$ Faculty of Archaeology, Leiden University, Netherlands; ${ }^{13}$ Department of Earth Sciences, Syracuse University, USA; ${ }^{14}$ Oxford Radiocarbon Accelerator Unit, UK

\section{Background}

In addition to being crucial to many archaeological studies, radiocarbon ages form the chronological basis for many Holocene and late Pleistocene paleoclimatic studies and paleoenvironmental reconstructions. The basic radiocarbon age calculation assumption of constant atmospheric ${ }^{14} \mathrm{C}$ content is not valid, however, due to solar- and geomagnetic-induced changes in production rate and ocean circulation changes. In order to compare radiocarbon chronologies with those derived from other means, such as ice core or U/Th dated sequences, it is necessary to calibrate against measurements of "known" age samples.

Calibration curves were originally based only on ${ }^{14} \mathrm{C}$ measurements of knownage tree-rings and a calibration curve for Holocene marine samples was constructed using the atmospheric data as input into a simple ocean-atmosphere box diffusion model. More recently, marine records, U-Th dated corals and foraminifera from varvecounted sediments of Cariaco Basin, combined with reservoir corrections, provide high-resolution atmospheric calibration beyond the range of the tree-ring record. The ocean-atmosphere box diffusion box model, however, is used for Holocene marine calibration where marine calibration data are generally not available with sufficient resolution and precision. After a disastrous start of multiple independent "calibration" data sets that yielded disparate calendar ages

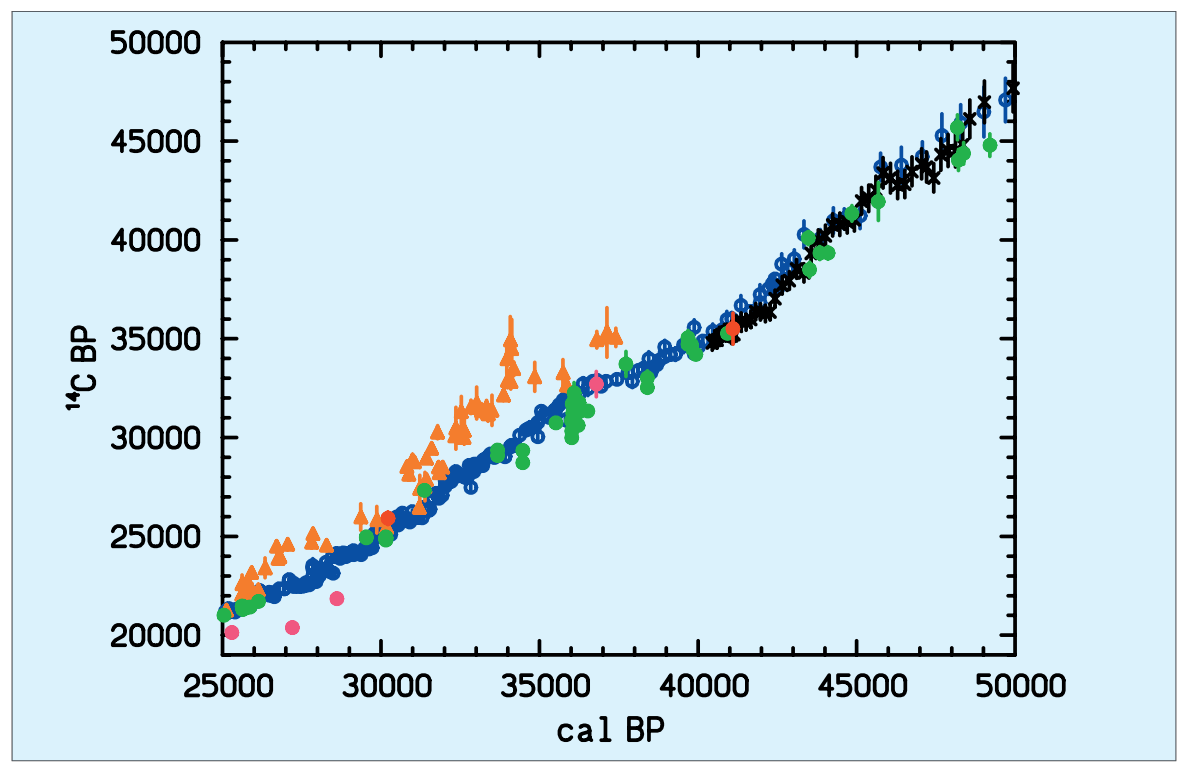

Figure 1: Selected ${ }^{14} \mathrm{C}$ data sets $>26 \mathrm{cal}$ kyr BP with calendar timescales based on U/Th dating, varve counts or through correlation to U/Th-dated speleothems. The marine and speleothem records are corrected with a constant reservoir or dead carbon fraction offset as specified in the original publication. Uncertainty is shown in the ${ }^{14} \mathrm{C}$ ages only as one standard deviation. Corals are given as solid circles: red (Bard et al., 2004); pink (Cutler et al., 2004); green (Fairbanks et al., 2005). The Cariaco Basin foraminifera data with the timescale from the correlation to the Hulu Cave is given as open blue circles (Hughen et al., 2006), Lake Suigetsu macrofossils as solid orange triangles (Kitagawa and van der Plicht, 2000), and Arabian Sea speleothem as black crosses (Weyhenmeyer et al., 2003).

and confusion among users, radiocarbon calibration curves have been constructed by small groups utilizing the best available and reproducible data sets, and ratified by the attendees at the International Radiocarbon Conferences. As the types of records available for calibration have diversified and the pros and cons of each realized, a larger, more formalized group has become a necessity. In 2002, the IntCal Working Group was created and has since met at a series of workshops funded by the Leverhulme Trust. The IntCal group has produced estimates of the calibration curves for the main carbon reservoirs: the Northern Hemisphere atmosphere (IntCal04), the Southern Hemisphere atmosphere (SHCal04), and the marine environment (Marine04). SHCal04 was the first ratified calibration curve for the Southern Hemisphere.

Most of the early calibration curves were constructed from a simple weighted 
average of all data within a 10- or 20-year bin. This ignored the uncertainty in the calendar axis, which can be significant for some records (non-tree-ring in particular). For the 2004 curves, Buck and Blackwell (2004) devised a tailor-made curve estimation method based on a random walk model (RWM), which takes account of the uncertainty in both the calendar ages and radiocarbon determinations that make up the raw calibration data, and formally acknowledges the covariance of the data points (induced by the fact that they all derive from the same underlying radiocarbon production mechanisms).

When the IntCal Working Group compiled the 2004 calibration data sets, many types of records were considered, including $\mathrm{U} / \mathrm{Th}$ dated corals, speleothems with U/Th age models, macrofossils from varved lake sediments, and foraminifera from varved and non-varved marine sediments with calendar age estimates (based on correlations to ice core records). Despite reasonably good agreement between many of these records beyond the range of the tree-ring data, however, only the corals and the foraminifera from the varved sediments were considered to meet the IntCal criteria for calibration back to $26 \mathrm{cal}$ kyr BP ( 0 cal BP = $A D$ 1950). As a result of these uncertainties, the group chose not to produce a calibration curve for this time period; instead a modeled estimate of the curve underlying all the data sets was determined and called NotCal04 to signify that it was NOT of calibration quality. Because of the lack of an internationally ratified calibration curve beyond $26 \mathrm{cal} \mathrm{kyr} \mathrm{BP}$, however, there has been a proliferation of "calibrations" based on individual data sets or selected compilations. Although such comparisons are valuable research tools for exploring possible leads and lags in the various carbon reservoirs and for providing tentative calendar age estimates, the mixed approaches make it difficult to compare records with different age estimates and, unfortunately, have the potential for causing significant uncertainty across the scientific and archeological community.

\section{The task ahead}

New and/or improved ${ }^{14} \mathrm{C}$ data sets for the time period beyond $26 \mathrm{cal}$ kyr BP were reported at the 19th International Radiocarbon Conference in Oxford (April 2006) and are generally in good agreement. Attendees of the conference business meeting agreed that the IntCal Working Group compile a standard "calibration" data set for the entire range of radiocarbon ( $<55 \mathrm{kyr} \mathrm{BP}$ ). Due to the rapid progress in the production of ${ }^{14} \mathrm{C}$ calibration data sets, the Radio- carbon community expressed the need for annual updates to the curves beyond the end of IntCal04 (currently at 26 cal kyr BP). These curves would provide tentative calendar age estimates and would be distinct from the explicitly higher-quality, tree-ring calibration data, and not ratified in a similar fashion to the IntCal curves. Ideally, data sets beyond 26 cal kyr BP should be referred to as 'comparison curves' until a 'calibration curve' is ratified. The NotCal04 estimate relied on modeling the (sometimes quite large) offsets between data sets using a random effect component, which we hope not to need for the next (non-ratified) output.

In order to provide more transparency and wider community input, an Oversight Committee including experts in a number of fields will be selected on the basis of online voting to be handled by the Radiocarbon journal. Funding is currently being sought for an IntCal Working Group meeting, including the Oversight Committee, to review and recommend the data to be included in the next IntCal extension, as well as for research assistance.

In addition, the current internationally ratified calibration curve, IntCal04, is due for a full update when the floating tree-ring extension from Germany and Switzerland are linked. This work is being undertaken through an ESF-EuroClimate grant to research groups in Heidelberg, Aixen-Provence, Budapest, Lund, Stockholm, Stuttgart-Hohenheim and Zurich, and is expected to be completed by 2007-8. If the estimated linkage of the floating tree-ring chronology is correct, then the calibration results of terrestrial radiocarbon dates from the end of the last glaciation to the beginning of the Younger Dryas chronozone will be significantly different from those derived from calibration using IntCal04.

It is anticipated that terrestrial records, such as the floating kauri tree-rings or terrestrial macrofossils from the new Lake Suigetsu cores, will eventually provide a terrestrial radiocarbon calibration to $55 \mathrm{kyr}$ with the detail necessary to resolve leads and lags in the climate system, or distinguish cause and effect of landscape changes related to early human occupation (e.g. of Australia). This cannot be achieved with the naturally smoothed marine and speleothem records (Fig. 1). In the meantime, terrestrial radiocarbon calibration or comparison curves beyond the end of the known-age tree-ring record will need to be constructed primarily from marine-based archives such as corals or foraminifera. The spatial and temporal variability of marine radiocarbon reservoir ages (MRA) is therefore an outstanding problem (c.f. Reimer \& Reimer; this issue). A corollary is also present in speleothem- based records, which have to make assumptions on the constancy or model-estimate of the dead carbon fraction.

It has been suggested that coupled ocean-atmosphere global circulation models (OGCMs) could provide some insight into past MRA. However, OGCMs have a difficult time accurately recreating the spatial distribution and pattern of natural and bomb ${ }^{14} \mathrm{C}$ in the ocean. Thus, these model simulations should not be thought of as the solution to estimate past reservoir age variations at present but more in terms of sensitivity experiments towards potential solutions. An updated and extended event stratigraphy approach such as that used by Bjorck et al. (2003), as well as further paleo-reservoir age measurements, where appropriate sequences exist, should be undertaken.

And finally: semantics. What should we call the tentative calendar age curves and the resulting estimates? There needs to be some short but easily understood abbreviation so that one can readily tell true calibrated radiocarbon ages (derived from the use of internationally agreed radiocarbon calibration curves) from more tentative calendar age estimates derived from the use of an interim curve based on a non-ratified compilation of potential calibration data.

Despite these uncertainties, if all goes well, radiocarbon users can expect an updated IntCal04 and a new compilation curve for calendar age estimation back to $55 \mathrm{kyr}$ BP in the near future. There are exciting times ahead.

\section{References}

Bard, E., Menot-Combes, G. and Rostek, F., 2004: Present status of radiocarbon calibration and comparison records based on Polynesian corals and Iberian Margin sediments, Radiocarbon, 46(3): 11891202.

Bjorck, S., Koc, N. and Skog, G., 2003: Consistently large marine reservoir ages in the Norwegian Sea during the Last Deglaciation, Quaternary Science Reviews, 22 (5-7): 429-435.

Buck, C.E. and Blackwell, P.G., 2004: Formal statistical models for estimating radiocarbon calibration curves, Radiocarbon, 46(3): 1093-1102.

Cutler, K.B., Gray, S.C., Burr, G.S., Edwards, R.L., Taylor, F.W., Cabioch, G., Beck, J.W., Cheng, H., Moore, J., 2004: Radiocarbon calibration to 50 kyr BP with paired ${ }^{14} \mathrm{C}$ and ${ }^{20}$ Th dating of corals from Vanuatu and Papua New Guinea. Radiocarbon, 46(3): 1127-1160.

Fairbanks, R.G., Mortlock, R.A., Chiu, T.-C., Cao, L., Kaplan, A., Guilderson, T.P., Fairbanks, T.W., Bloom, A.L., Grootes, P.M. and Nadeau, M.-J., 2005: Radiocarbon Calibration Curve Spanning 0 to 50,000 Years B.P. Based on Paired 230Th/234U/238U and ${ }^{14} \mathrm{C}$ Dates on Pristine Corals, Quaternary Science Reviews, 24(16-17): 1781-1796.

Hughen, K., Southon, J., Lehman, S., Bertrand, C. and Turnbull, J., 2006 Marine-derived ${ }^{14} \mathrm{C}$ calibration and activity record for the past 50,000 years updated from the Cariaco Basin, Quaternary Science Reviews, in press.

Kitagawa, H. and van der Plicht, J., 2000: Atmospheric radiocarbon calibration beyond 11,900 cal BP from Lake Suigetsu laminated sediments, Radiocarbon, 42(3): 369-380.

Weyhenmeyer, C.E., Burns, S.J., Fleitmann, D., Kramers, J.D., Matter, A. Waber, H.N. and Reimer, P. J., 2003: Changes in atmospheric ${ }^{14} \mathrm{C}$ between 55 and $42 \mathrm{ky}$ BP recorded in a stalagmite from Socotra Island, Indian Ocean, EOS Transactions, 84(46): Fall Meet. Suppl. Abstract PP32B-0298. 